\title{
Seismological Society of America
}

\section{A SEMI-EMPIRICAL APPROACH TO PREDICTION OF LONG-PERIOD GROUND MOTIONS FROM GREAT EARTHQUAKES}

\author{
By Hiroo Kanamori
}

\begin{abstract}
Predictability of long-period (1 sec or longer) ground motions generated by long strike-slip earthquakes such as the 1906 San Francisco and the 1857 Fort Tejon earthquakes, is investigated. Most large earthquakes are complex multiple events at this period range, and the resulting ground motion may be synthesized by convolving the ground motions of the individual event with the source function that describes the space-time history of the multiple shock sequence. Since it is not possible to predict deterministically the complexity of the rupture propagation, a semi-empirical approach was taken. For the ground motion from the individual events, the displacement records observed for the 1968 Borrego Mountain, California, earthquake were used after correcting for the distance and the radiation pattern. These records which were used as an empirical Green's function for the individual events were superposed, with some randomness, to produce ground motions resulting from a large earthquake. The models were constrained by gross seismological data at three periods. At $1 \mathrm{sec}$ they are constrained by the observed upper bound of the local magnitude $\left(M_{L}=7 \frac{1}{4}\right)$, and, at about $10 \mathrm{sec}$, by the upper bound of the seismic moment of the individual event of multiple shocks $\left(5 \times 10^{26}\right.$ dyne-cm). At very long periods, the models have the correct total seismic moment. The results obtained for a model of the 1857 earthquake indicate that: (1) the velocity response spectra of ground motions in the near-field are nearly flat at about $50 \mathrm{~cm} / \mathrm{sec}$ over the period range from 1 to $10 \mathrm{sec}$ under normal conditions; (2) under certain circumstances they can be as large as $150 \mathrm{~cm} / \mathrm{sec}$; (3) the maximum duration of the ground motion is $6 \mathrm{~min}$. These results are considered reasonable because they satisfy all the seismological constraints currently available over a wide period range.
\end{abstract}

\section{INTRODUCTION}

The nature of ground motions caused by earthquakes is a subject of primary engineering interest. For most structures of engineering interest, relatively highfrequency ( $1 \mathrm{~Hz}$ or higher) ground motions are most important. However, in view of the recent increase of large structures such as high-rise buildings, oil tanks, suspension bridges, reservoirs, and off-shore oil drilling platforms which have long resonance periods, more detailed knowledge of long-period ( 1 to $10 \mathrm{sec}$ ) ground motions is becoming increasingly important.

For short-period ground motions, a substantial amount of strong-motion data is available for various design purposes. However, data of very long-period waves, in particular those from very large earthquakes, are very few mainly because of the infrequent occurrence of such large earthquakes. Consequently, the nature of longperiod ground motions from great earthquakes has been inferred from the results 
obtained from smaller events (e.g., Jennings et al., 1968; Hanks, 1976). The past decade has seen significant progress in our understanding of the nature of large earthquakes, and it has become feasible to take a more direct approach to this problem by using seismological methods.

Various numerical methods have been developed to compute ground motions from a dislocation source (e.g., Aki, 1968; Haskell, 1969; Helmberger and Malone, 1975; Kawasaki et al., 1973, 1975; Herrmann and Nuttli, 1975a, b; Swanger and Boore, 1978). However, in applying these techniques to very large earthquakes, complexity of the rupture propagation must be known in detail. Unfortunately, such details are presently unknown, although some details of a large multiple-shock sequence have been unraveled (Kanamori and Stewart, 1978; Rial, 1978). Butler and Kanamori (1979) attempted a direct modeling procedure to compute long-period ground motions resulting from large strike-slip earthquakes. In the study of Butler and Kanamori, the complexity of rupture propagation had to be included in a somewhat ad hoc fashion.

In the present paper, we take a semi-empirical approach by using, as much as possible, various seismological data on the local magnitude, $M_{L}$, the source complexity of large earthquakes, and near-field displacement records observed for large earthquakes. We are primarily concerned with very long-period ( 1 to $10 \mathrm{sec}$ ) ground motions generated by a great earthquake, especially by a long strike-slip earthquake such as the 1906 San Francisco or the 1857 Fort Tejon earthquakes.

\section{METHOD}

In principle, if the geometric shape and size of the fault plane, $S$, the slip $\vec{D}(\vec{r}, t)$ on the fault plane as a function of position $\vec{r}$ and time $t$, and the structure of the propagation medium are known, one can accurately compute the ground motion. However, in actual problems the slip $\bar{D}(\vec{r}, t)$ can be a very complex function and the structure is not known in detail. Even if the structure is reasonably well known, it is usually laterally heterogeneous and the computation of the response is exceedingly cumbersome.

For relatively small events (source dimension $\leqslant 50 \mathrm{~km}$ ), deterministic source models with a simple dislocation function have been successfully used to compute ground motions at the period range of our interest ( 1 to $10 \mathrm{sec})$. Examples include: 1966 Parkfield earthquake (Aki, 1968; Haskell, 1969), 1943 Tottori earthquake (Kanamori, 1972), 1971 San Fernando earthquake (Mikumo, 1973a; Trifunac, 1974; Heaton and Helmberger, 1979), 1969 Gifu earthquake (Mikumo, 1973b), 1968 Saitama earthquake (Abe, 1974), 1968 Borrego Mountain earthquake (Heaton and Helmberger, 1977), 1973 Morgan Hill earthquake (Helmberger and Malone, 1975), and the 1976 Brawley earthquake (Heaton and Helmberger, 1978). However, when the source dimension becomes very large (e.g., longer than $100 \mathrm{~km}$ ), the source process cannot be modeled by a simple smooth dislocation function even for the period range longer than $1 \mathrm{sec}$. Many studies have indicated that most large earthquakes are complex multiple events at this period range. For example, the 1976 Guatemala earthquake (Kanamori and Stewart, 1978) can be modeled by approximately 10 events with $M_{S} \simeq 6.5$ to 7 (fault length 10 to $20 \mathrm{~km}$ ) which occurred in sequence along the fault. Stewart and Kanamori (1978) found complexity similar to this for an earthquake on the Anatolian Fault. These examples are shown in Figure 1. The ground motion from this type of earthquake may be computed by convolving the ground motion of the individual event with the source function describing the space-time history of the multiple shock sequence. 
However, in actual earthquakes, these point sources interfere with each other, producing very complex ground motions in the near field even at period ranges from 1 to 10 sec. Since it is not possible to predict the details of such interference pattern deterministically, we use gross seismological data to constrain the model. Specifically, we use the local magnitude $M_{L}$ and the result of multiple-shock analysis of large earthquakes. The former constrains the strength of the ground motion at about $1 \mathrm{sec}$, and the latter at about $10 \mathrm{sec}$.

Kanamori and Jennings (1978) and Jennings and Kanamori (1979) used a large number of strong-motion records and seismoscope records to determine $M_{L}$ for many large earthquakes. In particular, for the 1976 Guatemala earthquake and 1906 San Francisco earthquake, special efforts were made for calibration of the method and the instrurnents. The results are summarized in Figure 2 where the local magnitude $M_{L}$ is plotted against the surface-wave magnitude $M_{S}$. Although the data are still relatively sparse, a clear indication of saturation of the $M_{L}$ scale is seen; $M_{L}$ seems to be bounded at about $7 \frac{1}{4}$. This upper bound provides an important constraint on the amplitude of strong motions at the period of $1 \mathrm{sec}$. Saturation of $M_{L}$ has been

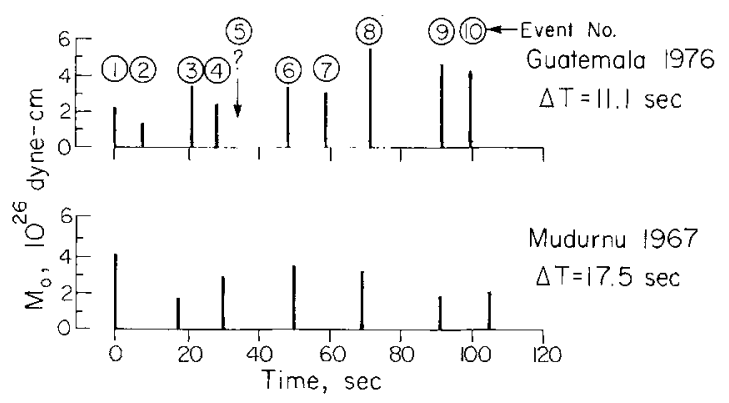

FIg. 1. Source-time series for the 1976 Guatemala earthquake (Kanamori and Stewart, 1978) and the 1967 Mudurnu earthquake (Turkey) (Stewart and Kanamori, 1978). The ordinate shows the seismic moment of each event of the multiple shock sequences, and the event numbers are shown for the Guatemala earthquake. $\Delta T$ is the average separation between two consecutive events.

interpreted in terms of a finite effective stress acting on the fault plane (Brune, 1970).

Kanamori and Stewart (1978), Rial (1978), and Stewart and Kanamcr (1978) analyzed complex multiple shocks to determine the seismic moment of the individual events which constitute the multiple shock. As shown in Figure 1 the maximum seismic moment of the individual events of the 1976 Guatemalan earthquake is about $5 \times 10^{26}$ dyne-cm. For the Caracas earthquake (Rial, 1978) it is $2 \times 10^{26}$ dyne$\mathrm{cm}$. Also, among all strike-slip events which can be considered to be a relatively simple event at the period range of about 5 to $10 \mathrm{sec}$, no event has a seismic moment larger than $5 \times 10^{26}$ dyne-cm [e.g., 1943 Tottori earthquake, $3.6 \times 10^{26}$ dyne-cm, Kanamori (1972); for other events, see table 1 of Kanamori and Anderson, 1975]. These results suggest an upper bound of seismic moment of $5 \times 10^{26}$ dyne-cm at periods of about $10 \mathrm{sec}$. This value will be used to constrain the amplitude at these periods. With these constraints from gross seismological data, we illustrate the method for the 1976 Guatemala earthquake.

Since the multiple shock model obtained by Kanamori and Stewart (1978) (Figure 1) was derived by using a point source, it does not provide the spatial distribution 
of the individual shocks uniquely. Here, we use a spatial distribution of point sources shown in Figure 3 (also Table 1) to model the faulting sequence of the Guatemala earthquake. The event numbers shown in Figure 3 refer to those in Figure 1. This model is obtained by assuming that the rupture started from event 1 and was propagated bilateraily with a rupture velocity of $2 \mathrm{~km} / \mathrm{sec}$. This geometry is not

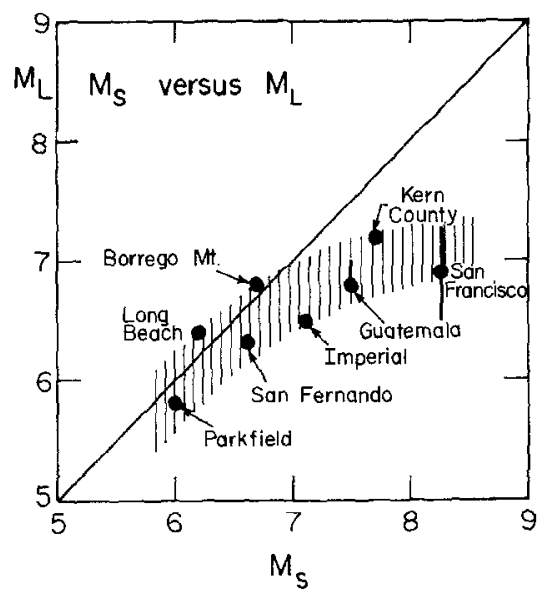

FIG. 2. Relation between $M_{L}$ (local magnitude) and $M_{S}$ (surface-wave magnitude). The local magnitudes used here are obtained from either strong-motion records (Kanamori and Jennings, 1978) or seismoscope records (Jennings and Kanamori, 1979) and represent the strength of the ground motion near the epicentral area at the period of about $1 \mathrm{sec}$.

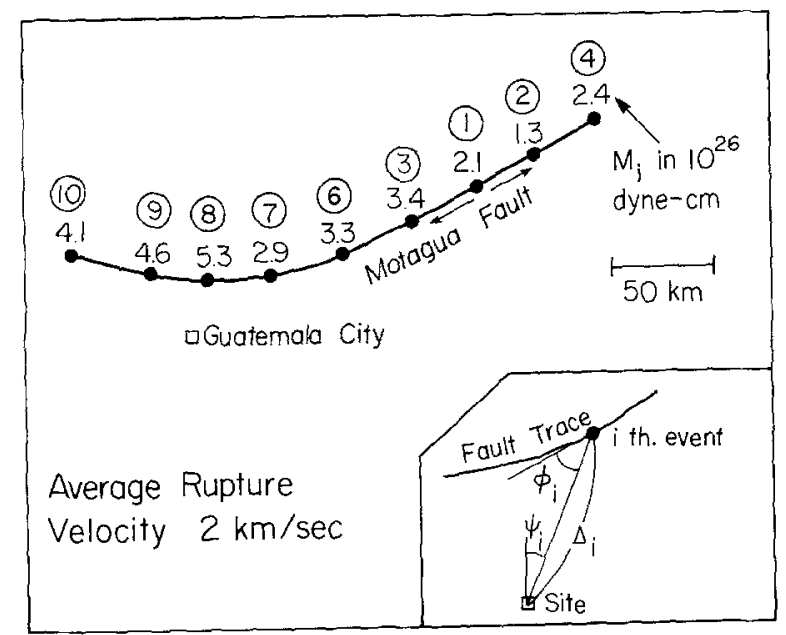

Fig. 3. Geometry of the fault model used for the 1976 Guatemala earthquake. Inset, definition of $\Delta_{i}$, $i$, and $\psi_{i}$.

unique, and other geometries that produce the time sequence shown in Figure 1 can be constructed. However, the choice of the geometry is not particularly important for our present purpose. As we will show later, since the overall sequence of the events will be extensively randomized, the particular geometry of the model would 
not directly affect the overall feature of the final result. Furthermore, there is no obvious reason to believe that earthquakes in the future have exactly the same geometry as the 1976 event. Our fundamental assumption here is that the 1976 event represents the overall complexity of large earthquakes of this type.

We now attempt to compute long-period ground motions at Guatemala City (hereafter, called the site) resulting from the fault model shown in Figure 3. For this distributed point-source model, the displacement at the site can be expressed as

$$
u(t)=\sum_{i=1}^{N} f_{i}\left(t-\eta_{i}\right)
$$

where $f_{i}(t)$ is the displacement at the site due to the $i$ th point source, $t$ is the time, $N$ is the total number of the point source, and $\eta_{i}$ is the delay due to the rupture propagation. In general, both $f_{i}$ and $u$ are vectors. First we need to obtain $f_{i}(t)$.

TABLE 1

Geometry of the Model for the 1976 Guatemala

EARTHQUAKE*

\begin{tabular}{ccrrrr}
\hline Event No. & $\begin{array}{c}M_{i} \\
10^{26} \mathrm{dyne-cm}\end{array}$ & $\begin{array}{c}\phi_{i} \\
(\mathrm{deg})\end{array}$ & $\begin{array}{c}\Delta_{i} \\
(\mathrm{~km})\end{array}$ & $\begin{array}{c}\psi_{i} \\
(\mathrm{deg})\end{array}$ & $\begin{array}{c}\eta_{i} \dagger \\
(\mathrm{sec})\end{array}$ \\
\hline 4 & 2.4 & 0 & 223 & 65 & 28 \\
2 & 1.3 & 0 & 191 & 65 & 8 \\
1 & 2.1 & 0 & 157 & 65 & 0 \\
3 & 3.4 & 0 & 121 & 65 & 20 \\
6 & 3.3 & 0 & 83 & 65 & 50 \\
7 & 2.9 & 40 & 49 & 55 & 60 \\
8 & 5.3 & 80 & 28 & 25 & 70 \\
9 & 4.6 & 135 & 36 & -35 & 90 \\
10 & 4.1 & 160 & 68 & -55 & 100 \\
\hline
\end{tabular}

* For the symbols used, see Figure 2.

$\dagger \eta_{i}$ is the delay due to the rupture propagation.

If the depth, the source-time function, the size of the individual event, and the crustal structure are known, the resulting ground motion can be calculated by using existing methods (e.g., Helmberger and Malone, 1975; Herrmann and Nuttli, 1975a, b; Heaton and Helmberger, 1977; Swanger and Boore, 1978; Butler and Kanamori, 1979). However, this is not always very easy for several reasons. First, although the source-time function (far-field) of the individual events of the Guatemala earthquake can be approximated roughly by a trapezoid at periods around $10 \mathrm{sec}$ (Kanamori and Stewart, 1978), it could be more complex at shorter periods (1 to $5 \mathrm{sec}$ ). Second, the distribution of dislocation as a function of depth is not known in detail. For the 1968 Borrego Mountain earthquake, Burdick and Mellman (1976) and Heaton and Helmberger (1977) suggested a relatively concentrated source at a depth of $9 \mathrm{~km}$. Third, the structure between the source and the site is not very well known; even if it is known, it is probably highly heterogeneous laterally and the computation becomes very cumbersome.

In order to circumvent these difficulties we use an empirical method. Instead of computing $f_{i}(t)$ numerically, we use observed seismograms from an earthquake comparable, both in size and geometry, to the individual event of the Guatemala earthquake. The idea of using an observed seismogram of a small earthquake as a 
Green's function for computing the displacement from a larger earthquake has been utilized by Hartzell (1978).

For our present purpose, the 1968 Borrego Mountain earthquake is the most adequate to represent the individual events of the Guatemala earthquake because: (1) the magnitude $\left(M_{S}=6.7, M_{L}=6.8\right.$, see Kanamori and Jennings, 1978) is comparable to the individual event of the Guatemala earthquake, (2) the mechanism (nearly vertical strike-slip) is very similar to that of the Guatemala earthquake and the Fort Tejon type earthquakes, (3) very detailed source models are known
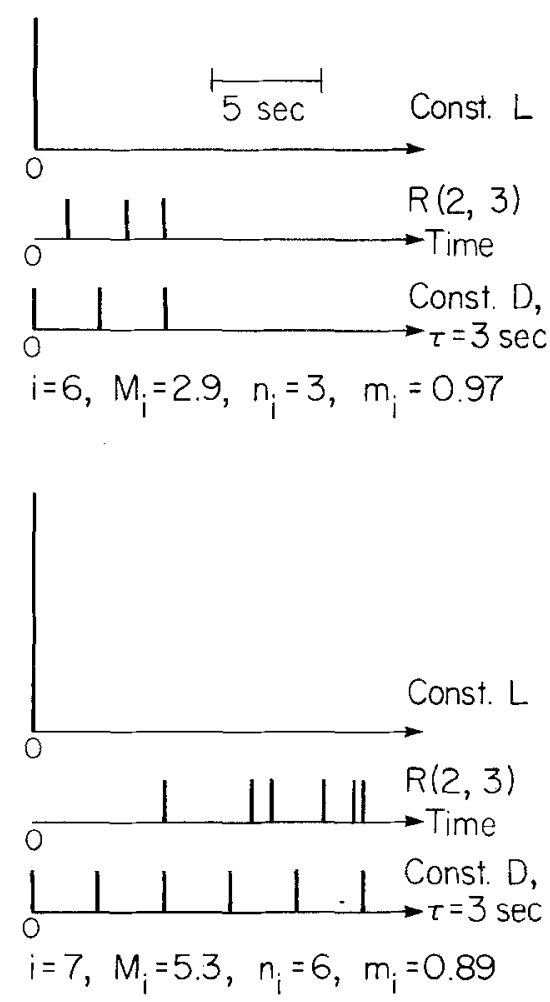

FIG. 4. Source-time sequence for event 6 (upper) and event 7 (lower) of the Guatemala earthquake. The Const. $\mathrm{L}$ model, a random model $\mathrm{R}(2,3.0)$ and Const. D model are shown. $M_{i}$ is the seismic moment of the $i$ th event in $10^{26}$ dyne-cm, $m_{i}$ is the seismic moment of the unit event (in $10^{26} \mathrm{dyne}-\mathrm{cm}$ ), and $n_{i}$ is the number of unit events used to represent the $i$ th event.

(Burdick and Mellman, 1976; Heaton and Helmberger, 1977), and (4) high-quality displacement records are available at four stations in a distance range from 67 to $150 \mathrm{~km}$ (see Figures 5 and 6); the path to these stations samples various geological structures.

In using this method we first make the following assumptions

1. For a vertical strike-slip mechanism, the major contribution comes from $S H$ and Love waves (Heaton and Helmberger, 1977; Butler and Kanamori, 1979); the contribution from Rayleigh waves is negligible. We can therefore assume that $f_{i}(t)$ has only transverse component and is governed by the Love-wave radiation pattern $\cos 2 \phi_{i}$ where $\phi_{i}$ is the azimuth measured from the fault strike (see Figure 3 for geometry). In practice, the displacement from a strike-slip event has considerable amplitude on the radial component due to the structural 
heterogeneity and small nonstrike-slip components of the source. This is particularly obvious at stations in the nodal direction of $S H$-wave radiation. However, when the amplitude is corrected for the radiation pattern, the transverse component is usually dominant.

2. The effect of dispersion is not considered for the distance range studied here, i.e., 30 to $150 \mathrm{~km}$. Although this assumption is very crude, the effect of dispersion is probably not very important for our purpose because the overall duration of the ground motion is mainly governed by the entire rupture propagation along the fault rather than the dispersion of the individual point source.

3. The effect of attenuati $n$ is also ignored. For the period range considered here, this is a reasonable assumption. For example, for $Q=300$ and $\Delta$ (distance) $=$

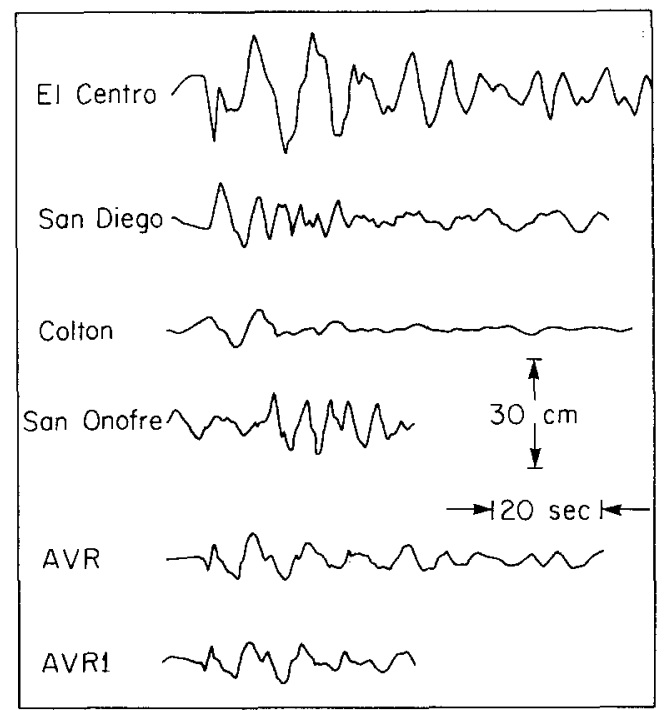

FIG. 5. Transverse $(\mathrm{SH})$ component of the ground displacement observed for the 1968 Borrego Mountain earthquake. For the location of the stations El Centro, San Diego, Colton, and San Onofre, see Figure 6. AVR is the average of El Centro, San Diego and Colton, and AVR1 is that of all four stations. The amplitudes are normalized to that at a distance of $50 \mathrm{~km}$ and for the direction of the maximum of the radiation pattern of the Love wave.

$150 \mathrm{~km}$, the amplitude diminution factor $\exp (-\pi \Delta / Q T c)$ is about 0.9 at a period of $5 \mathrm{sec}$, where a phase velocity $c=3 \mathrm{~km} / \mathrm{sec}$ is used.

With these assumptions, the amplitude decays as $1 / \sqrt{\Delta}$, and $f_{i}(t)$ can be written as

$$
f_{i}(t)=\sqrt{\frac{\Delta_{0}}{\Delta_{i}}} \frac{\cos 2 \phi_{i}}{\cos 2 \phi_{0}} g_{i}\left[t-\frac{1}{c}\left(\Delta_{0}-\Delta_{i}\right)\right]
$$

where $g_{i}(t)$ is the displacement due to the $i$ th point source at distance $\Delta_{0}$ and azimuth $\phi_{0} ; c$ is the phase velocity which will be assumed to be $3 \mathrm{~km} / \mathrm{sec}$.

By using (2), equation (1) can be written as

$$
u(t)=\sum_{i=1}^{N} \sqrt{\frac{\Delta_{0}}{\Delta_{i}}} \frac{\cos 2 \phi_{i}}{\cos 2 \phi_{0}} g_{i}\left[t-\frac{1}{c}\left(\Delta_{0}-\Delta_{i}\right)\right]
$$


The next step is to express $g_{i}(t)$ in terms of the observed seismograms of the Borrego Mountain earthquake shown in Figure 5. One significant difference between the Borrego Mountain earthquake and the individual event of the Guatemala earthquake is in the seismic moment. The seismic moments of the individual events of the Guatemala earthquake range from 1.3 to $5.3 \times 10^{26}$ dyne-cm and is significantly larger than that of the Borrego Mountain earthquake which ranges from 0.7 to 1.1 $\times 10^{26}$ dyne-cm, (Burdick and Mellman, 1976; Heaton and Helmberger, 1977). Hence, it is necessary to add 1 to 6 (in general $n$ ) Borrego Mountain earthquakes to represent each point source of the Guatemala earthquake. There are at least three ways of doing this. First, $n$ Borrego Mountain earthquakes are added simultaneously. This procedure results in a most energetic event because high-frequency waves as well as low-frequency waves are added in phase resulting in totally constructive interference. Second, $n$ Borrego Mountain earthquakes are added with a uniform time delay of $\tau$ with the total energy spread out over $n \tau$. In this case, short-period waves are diminished because of destructive interference similar to that which

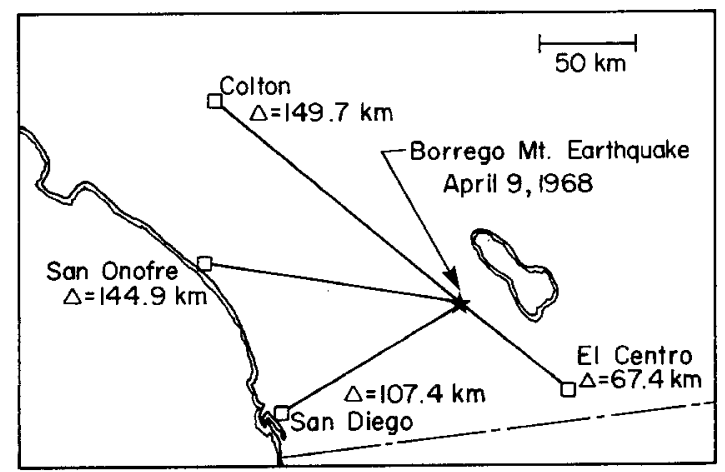
5.

FIG. 6. The location of the 1968 Borrego Mountain earthquake and the four stations shown in Figure

occurs for a uniform propagating source (e.g., Haskell, 1964). The third model is intermediate between these two models; $n$ Borrego Mountain earthquakes are added randomly in time, over a time interval of $n \tau$. When the $n$ events cluster in time, this model approaches the first model, and when they are distributed uniformly in time, it approaches the second one.

The first model represents an extreme case which is probably very unreasonable. In this case, since the amplitude is multiplied by $n$, the local magnitude of the total event becomes significantly ( $\log n$ times) larger than the Borrego Mountain earthquake. However, as shown by Jennings and Kanamori (1979), the local magnitude of the Guatemala earthquake $\left(M_{L}=6.8\right)$ is essentially the same as that of the Borrego Mountain earthquake, $M_{L}=6.8$ (Kanamori and Jennings, 1978).

The second model, on the other hand, represents the other extreme. Such a regular distribution is very unlikely to represent complex natural events. However, these two extreme models are useful as the upper and the lower bounds of the actual situation. In this paper, the first and the second model are called the Const. L model and the Const. D model, respectively, for the following reasons (see Figure 4). In the elastic dislocation model, the far-field source-time function can be represented by a triangular or a trapezoidal function. For the 1968 Borrego Mountain earthquake, 
Burdick and Mellman (1976) and Heaton and Helmberger (1977) used a triangular source-time function. In these models, the width and the area of the triangular (or trapezoidal) function are proportional to the fault length $L$ and the seismic moment, respectively. Since $n$ events are added simultaneously in the first model, the corresponding source-time function becomes $n$ times taller than that of each event, but the width remains unchanged. Therefore it is called the Const. L model. On the other hand, in the second model, $n$ triangular source-time functions are staggered in time so that the effective width becomes $n \tau$ but the dislocation $\mathrm{D}$ remains constant. Since the actual source-time function is more complex than the simple triangular function, the above picture is only approximate. Nevertheless, these names are convenient for understanding the physical picture of the models. The third model is called the $\mathrm{R}$ model, where $\mathrm{R}$ stands for random.

In practice we obtain $g_{i}(t)$ as follows. Figure 5 shows the transverse component of the displacement record obtained at four stations, El Centro, San Diego, Colton, and San Onofre (see Figure 6). These records are obtained from strong-motion seismograms (California Institute of Technology, 1969 to 1976) by numerically rotating the two horizontal components into a transverse component.

The amplitude of the record at each station has been multiplied by

$$
\sqrt{\frac{\Delta_{k}}{\Delta_{0}}} \frac{\cos 2 \phi_{0}}{\cos 2 \phi_{k}}
$$

where $\Delta_{k}$ and $\phi_{k}$ are the distance and the azimuth (measured from the fault strike) to the individual station and $\Delta_{0}$ and $\phi_{0}$ are a reference distance and azimuth, here $\Delta_{0}=50 \mathrm{~km}$ and $\phi_{0}=0$ (loop direction). This operation equalizes these records to those at distance $\Delta_{0}$ and azimuth $\phi_{0}$ under the assumptions made above. Therefore, if the propagation path is identical to all the stations these wave trains should have the same amplitude. The difference in the amplitude exhibited by Figure 5 is probably caused by a large lateral heterogeneity of the propagation path. Heaton and Helmberger (1977) and Swanger and Boore (1978) have shown that the wave form at EI Centro can be explained in terms of a crustal wave guide of the Imperial Valley. In order to obtain an average of the displacement function, the average (straight average without delay) of the records at El Centro, San Diego, and Colton is taken and is shown as AVR in Figure 5. We consider that this record represents the average effect of the complex crustal structure. Including the record at San Onofre in the average does not change the result very much as shown by AVR1 in Figure 5. Since the El Centro record represents the rather special situation of the Imperial Valley (Heaton and Helmberger, 1977; Swanger and Boore, 1978), we will primarily use the AVR trace in the following calculations. However, since the El Centro record is very well understood in terms of response function of the crust we will also use it in the following analysis. We denote these functions by $g_{0}(t)$, and call it the empirical Green's function.

By using $g_{0}(t)$ we can write $g_{i}(t)$ as follows. Since the seismic moment $M_{i}$ of the individual event is not an integral multiple of the seismic moment of the Borrego Mountain earthquake $m_{0}\left(m_{0}=0.83 \times 10^{26}\right.$ dyne-cm is used) we first define $n_{i}$ by

$$
n_{i}=\left[\frac{M_{i}}{m_{0}}\right]
$$


where [ ] means the integer nearest to the argument. Then the Const. $\mathrm{L}$ model is expressed by

$$
g_{i}(t)=\left(\frac{m_{i}}{m_{0}}\right) n_{i} g_{0}(t)
$$

where $m_{i}=M_{i} / n_{i}$. Similarly, the Const. D model is given by

$$
g_{i}(t)=\left(\frac{m_{i}}{m_{0}}\right) \sum_{j=1}^{n_{i}} g_{0}(t-j \tau)
$$

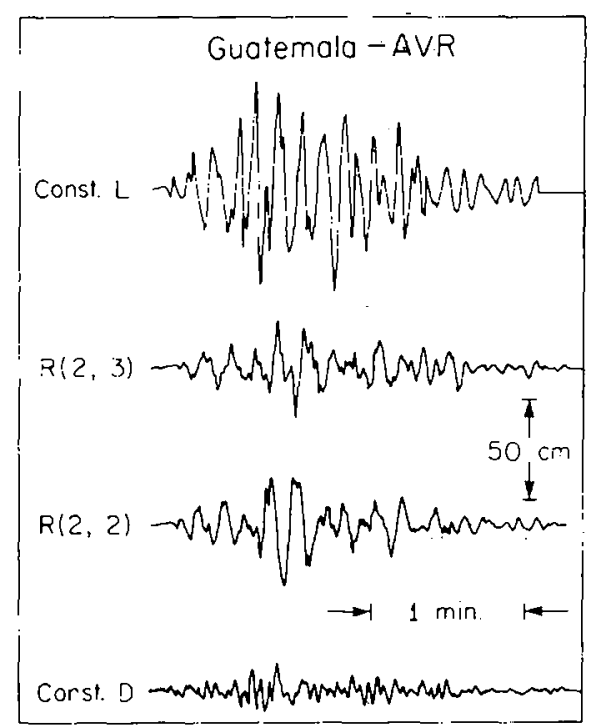

Fig. 7. Computed ground motions at Guatemala City for four rupture models of the 1976 Guatemala earthquake. The AVR record shown in Figure 5 is used for the empirical Green's function.

and the $R$ model can be written as

$$
g_{i}(t)=\left(\frac{m_{i}}{m_{0}}\right) \sum_{j=1}^{n_{i}} g_{0}\left(t-\tau_{j}\right)
$$

where $\tau_{j}\left(j=1,2,3, \ldots, n_{i}\right)$ are the random time delays chosen between 0 and $n_{i} \tau$. In equations (5), (6), and (7), $m_{i} / m_{0}$ is nearly equal to 1 .

Combining equation (3) with either (5), (6), or (7), the displacement at the site can be computed. The direction of the displacement $u$ given by equation (3) changes as the rupture propagates along the fault; $u(t)$, therefore, represents a two-dimensional vectorial displacement. Although the standard NS and EW components are also calculated from $u(t)$ in the present study, only $u(t)$ will be shown in the following figures. Since $u(t)$ rotates over a large azimuthal range, the maximum amplitude of the NS or the EW component is about the same as that of $u(t)$. In generating the random series $\tau_{j}$, we used a random number subroutine RND (Prime 
Computer, Inc., 1977) which generates a series of random numbers for a given preset index. For the first event of the multiple shock sequence, $n_{1}$ random numbers $r_{1}, r_{2}$, $\ldots, r_{n_{1}}$ are generated for a given preset index $I$. Then $\tau_{1}, \tau_{2}$, and $\tau_{n_{1}}$ are determined by

$$
\tau_{l}=\frac{r_{l}}{\max \left[r_{k}\right]} n_{1} \tau, \quad l=1, \ldots, n_{1}
$$

For the second event, $I$ is replaced by $I+1$ and the same procedure is applied. This procedure is repeated fo. all the events of a multiple shock. Since the model is represented in this scheme by two parameters, $I$ and $\tau$, the $\mathbf{R}$ model thus generated is denoted by $R(I, \tau)$. The examples shown in Figure 4 are for events 6 and 7 of the Guatemala earthquake model.

TABLE 2

SUMmaRy OF THE RESULTS OBTAINED FOR THE 1976

Guatemala Earthquake

\begin{tabular}{lrc}
\hline \multicolumn{1}{c}{ Model } & PP amp* ${ }^{*}(\mathrm{~cm})$ & $M_{L} \dagger$ \\
\hline G - AVR & & \\
Const. L & 100.6 & 7.1 \\
Const. D $(\tau=3 \mathrm{sec})$ & 23.5 & 6.6 \\
R $(2,3.0)$ & 48.1 & 6.8 \\
R $(4,3.0)$ & 73.8 & 6.6 \\
R $(2,5.0)$ & 47.6 & 6.8 \\
R $(2,2.0)$ & 51.7 & 6.7 \\
G - ELC & & \\
Const. L & 272.4 & 7.5 \\
Const. D $(\tau=3 \mathrm{sec})$ & 68.0 & 7.0 \\
R $(2,3.0)$ & 116.8 & 7.1 \\
R $(4,3.0)$ & 175.3 & 7.0 \\
R $(2,5.0)$ & 94.9 & 7.1 \\
\hline
\end{tabular}

* PP amp is the peak-to-peak amplitude of the computed ground motion.

$\dagger M_{L}$ is the local magnitude computed with a distance of $30 \mathrm{~km}$.

\section{Results for the Guatemala Earthquake}

Figure 7 shows the results for four different rupture models of the 1976 Guatemala earthquake. The fault geometry used for the calculation is shown in Figure 3 and the displacement AVR is used for $g_{0}(t)$. The top trace is for the Const. L model which, as expected from the discussion in the previous section, shows the largest amplitude. The bottom trace is for the Const. D model $(\tau=3.0 \mathrm{sec})$ which has the smallest amplitude. The middle two traces are for two random models with the parameters $I$ and $\tau$ indicated in the parentheses. Although these two traces differ in details, the overall feature is very similar with a peak-to-peak amplitude of about 50 $\mathrm{cm}$. We made similar computations by using the El Centro record ELC. The results are summarized in Table 2. 
Unfortunately, no observed strong-motion record is available for the Guatemala earthquake to compare with the results obtained here. One check can be made in terms of the local magnitude $M_{L}$. In Table 2, the local magnitude $M_{L}$ is listed for each model. The local magnitude $M_{L}$ is computed by convolving the individual displacement with the instrument response of the Wood-Anderson seismograph and by measuring the maximum trace amplitude. The distance used for the calculation

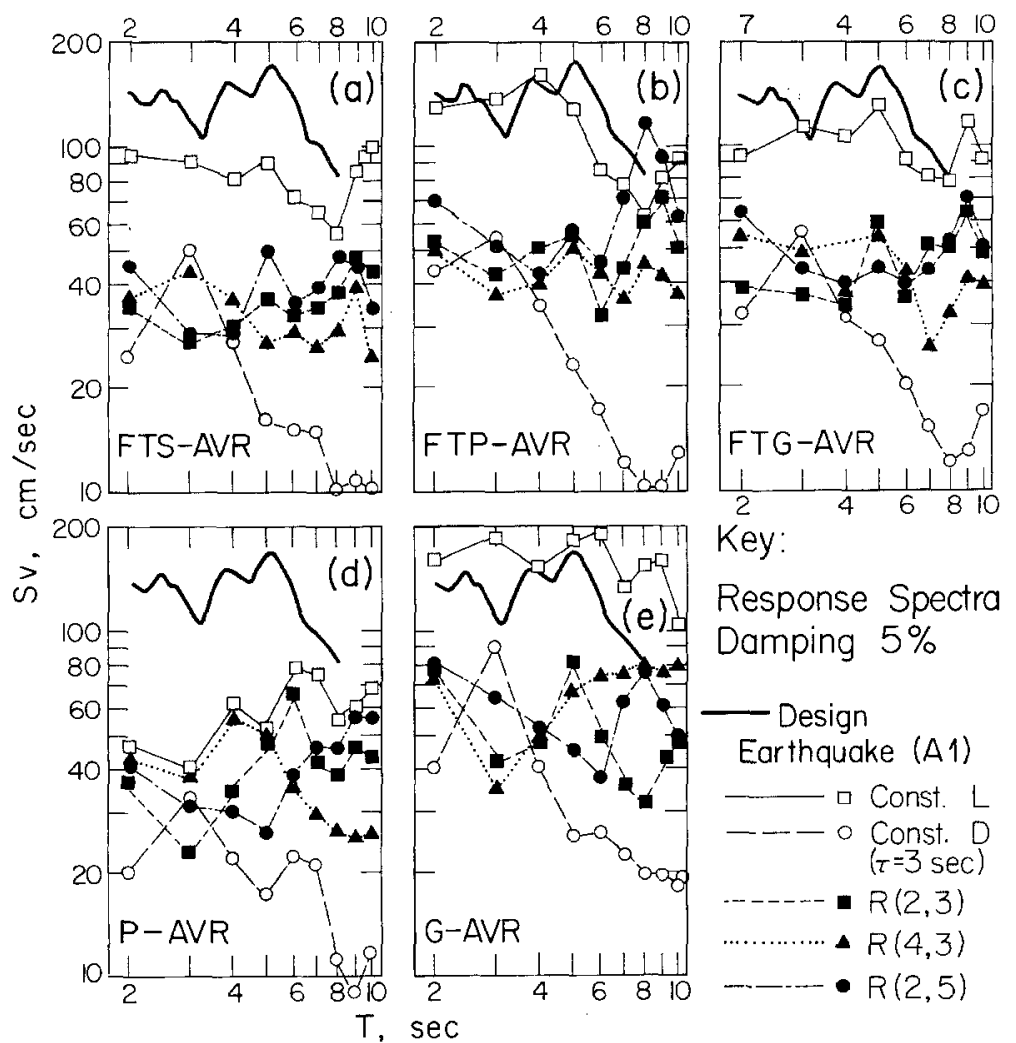

FIG. 8. Response spectra (velocity) computed for the five earthquake models. For each earthquake, five rupture models computed for the AVR Green's function are shown. Open symbols represent deterministic models; closed symbols, random models. The spectra are computed for a damping equal to 5 per cent of the critical damping. The heavy solid curve shows the spectrum of the Al design earthquake (Jennings et al., 1968).

of $M_{L}$ is measured between the site (Guatemala City) and the nearest point on the fault. Since the equalization method used in this study is not very appropriate at the relatively short-period range where $M_{L}$ is measured, these values should be considered approximate. Nevertheless, it is interesting to observe that the values for the random models with the AVR Green's function range from 6.6 to 6.8, which agrees very well with the value, 6.8, obtained by Jennings and Kanamori (1979) using the same distance.

In order to show the spectral structure of these ground motions, response spectra $S_{V}$ (velocity) with a damping of 0.05 (5 per cent of critical damping) are computed and shown in Figures $8 \mathrm{e}$ and $9 \mathrm{e}$. As expected, the Const. $\mathrm{L}$ and Const. D models bracket the random models except at 3 sec. This peak is probably caused by the 
regular interval of $3 \mathrm{sec}$ with which superposition of $g_{0}(t)$ is made. In Figures 8 and 9 the response spectrum for the design earthquake Al (Jennings et al., 1978) is shown for comparison. For all random models with the AVR trace as $g_{0}(t)$, the value of $S_{V}$ is about ${ }_{3}^{1}$ of the A1 earthquake at periods less than $5 \mathrm{sec}$. However, at periods larger than 5 sec, a significant difference in the trend is seen. The computed response spectra are essentially flat at periods longer than $5 \mathrm{sec}$ while the spectrum of the A1 earthquake decreases very sharply. When the ELC record is used for $g_{0}(t)$, the

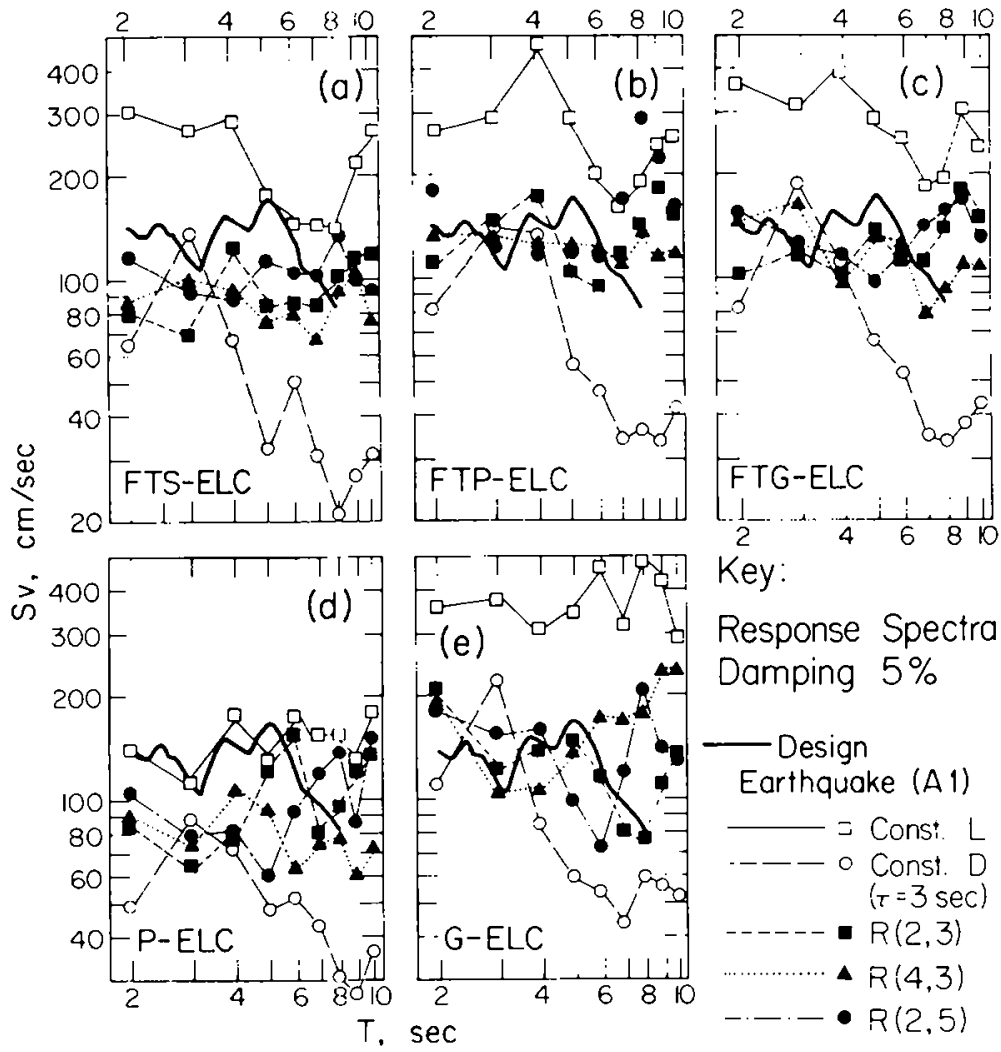

FIG. 9. Response spectra computed for the models with the ELC Green's function. For details see the caption for Figure 8.

computed spectra are about the same as that of the A1 earthquake at periods shorter than $5 \mathrm{sec}$.

\section{Fort Tejon-Type Earthquake}

We now use this method to investigate the nature of long-period ground motions which would result from a large strike-slip earthquake similar to the 1857 Fort Tejon, California, earthquake. The geometry of the fault is sketched in Figure 10. This geometry is the same as that used by Butler and Kanamori (1979). Unlike the Guatemala earthquake, no data are available concerning the complexity of rupture propagation associated with this earthquake. Even if the complexity is known, there is no obvious reason why the rupture should occur in the same manner, in a 
deterministic sense, as in the previous event. We therefore assume a geometry and proceed with the calculation.

According to Sieh (1978) the displacement in the 1857 Fort Tejon earthquake was nearly twice as large in the northwestern half of the fault (e.g., Carrizo Plain) as that in the southeastern half of the fault. In dividing the fault model into a series of point sources, we consider the fact that the seismic moment of the individual events of observed multiple shocks seems to be bounded at about $5 \times 10^{26}$ dyne-cm. On these grounds, we set up a model for a Fort Tejon type earthquake as shown in

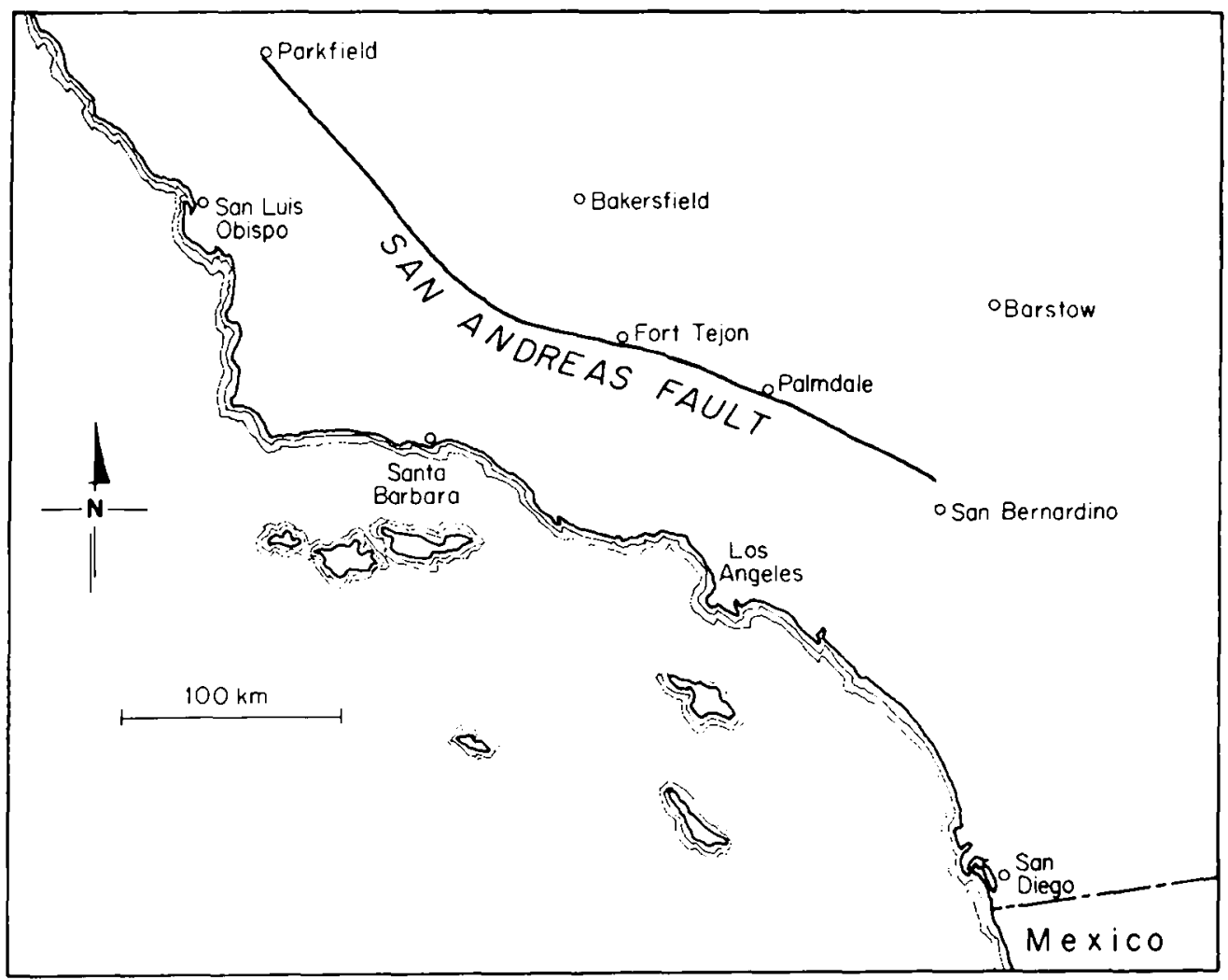

Fig. 10. The segment of the San Andreas Fault used for the computation of ground motions.

Figure 11. The events from 1 to 8 have a seismic moment of $5.6 \times 10^{26}$ dyne-cm and those from 9 to 17 have $2.8 \times 10^{26}$ dyne-cm; the total seismic moment is $7 \times 10^{27}$ dyne-cm which is close to the estimate of Sieh (1978).

Although this model appears too regular to represent the real fault structure, inclusion of randomness in adding elementary sources $\left[g_{0}(t)\right]$ at each point would randomize the overall characteristic of the fault. We assume an average rupture velocity of $2 \mathrm{~km} / \mathrm{sec}$.

In the following we consider four models. (1) FTS model: the rupture starts at the San Bernardino end (event 17) and propagates unilaterally toward the Parkfield end; (2) FTP model: the rupture starts at the Parkfield end (event 1) and propagates toward the San Bernardino end; (3) FTG model: the rupture starts at Gorman 
(event 9) and propagates bilaterally; (4) P model: this may be called a Palmdale earthquake which breaks only the southern part of the fault (events 11 to 17). The rupture is assumed bilateral starting at event 14.

In the following these model names are combined with either AVR or ELC to indicate the combination of the fault model and the empirical Green's function, $g_{0}(t)$ being used, e.g., FTS-AVR.

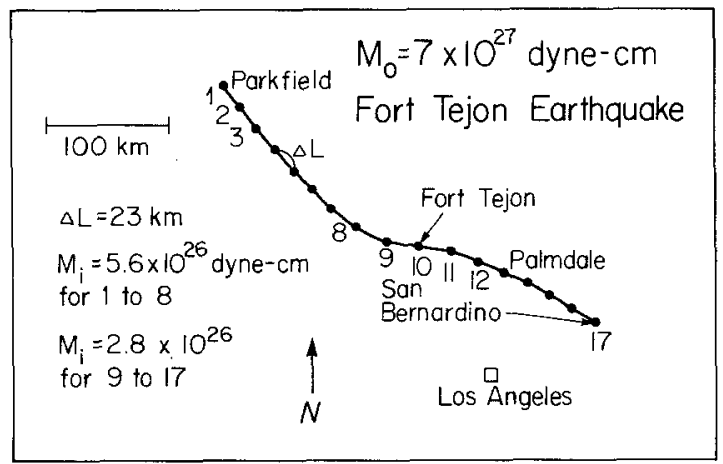

FIG. 11. Geometry of the fault model for four Fort Tejon-type earthquakes. The event numbers refer to those in Table 3.

TABLE 3

Geometry of the Model for Four Fort Tejon-Type Earthquakes

\begin{tabular}{|c|c|c|c|c|c|c|c|c|}
\hline \multirow{2}{*}{ Event No. } & \multirow{2}{*}{$\begin{array}{c}M_{L} \\
\left(10^{26} \mathrm{dyne-cm}\right)\end{array}$} & \multirow{2}{*}{$\begin{array}{c}\phi \\
\text { (deg) }\end{array}$} & \multirow{2}{*}{$\begin{array}{c}\Delta_{1} \\
(\mathrm{~km})\end{array}$} & \multirow{2}{*}{$\begin{array}{c}4 \\
\text { (deg) }\end{array}$} & \multicolumn{4}{|c|}{$\begin{array}{c}\eta_{i} \\
\text { (sec) }\end{array}$} \\
\hline & & & & & FTS & FTP & FTG & $\mathbf{P}$ \\
\hline 1 & 5.6 & 0 & 322 & -44 & 184 & 0 & 92 & - \\
\hline 2 & 5.6 & 0 & 301 & -44 & 172.5 & 11.5 & 80.5 & - \\
\hline 3 & 5.6 & 0 & 279 & -44 & 161 & 23 & 69 & - \\
\hline 4 & 5.6 & 0 & 257 & -44 & 149.5 & 34.5 & 57.5 & - \\
\hline 5 & 5.6 & 0 & 232 & -44 & 138 & 46 & 46 & - \\
\hline 6 & 5.6 & 0 & 210 & -44 & 126.5 & 57.5 & 34.5 & - \\
\hline 7 & 5.6 & 0 & 186 & -44 & 115 & 69 & 23 & - \\
\hline 8 & 5.6 & 20 & 160 & -41 & 103.5 & 80.5 & 11.5 & - \\
\hline 9 & 2.8 & 42 & 136 & -38 & 92.0 & 92 & 0 & - \\
\hline 10 & 2.8 & 50 & 118 & -30 & 80.5 & 103.5 & 11.5 & - \\
\hline 11 & 2.8 & 55 & 103 & -19 & 69 & 115 & 23 & 34.5 \\
\hline $\mathrm{I} 2$ & 2.8 & 60 & 88 & -7 & 57.5 & 126.5 & 34.5 & 23 \\
\hline 13 & 2.8 & 75 & 81 & 7 & 46 & 138 & 46 & 11.5 \\
\hline 14 & 2.8 & 85 & 77 & 22 & 34.5 & 149.5 & 57.5 & 0 \\
\hline 15 & 2.8 & 100 & 77 & 37 & 23 & 161 & 69 & 11.5 \\
\hline 16 & 2.8 & 115 & 85 & 51 & 11.5 & 172.5 & 80.5 & 23 \\
\hline 17 & 2.8 & 125 & 92 & 63 & 0 & 184 & 92.0 & 34.5 \\
\hline
\end{tabular}

We will consider a site south of downtown Los Angeles. The distance to this site is about $79 \mathrm{~km}$ from the nearest point on the fault. Geometries for these models are tabulated in Table 3. 
All the results computed for various fault models are tabulated in Tables 4 to 7 . In total, 70 models have been studied for both the Guatemala earthquake and the Fort Tejon earthquake.

Figure 12 shows the results for FTS-AVR computed for four different rupture models. The overall feature is the same as that for the Guatemala earthquake; the two deterministic models, Const. $\mathrm{L}$ and Const. $\mathrm{D}$, bracket the two random models. The response spectra are shown in Figure 8. The results for FTP-AVR, FTG-AVR, and P-AVR are shown in Figures A1, A2, and A3 in the Appendix.

TABLE 4

SUMMARY OF THE RESULTS FOR THE FTS MODEL

\begin{tabular}{|c|c|c|c|}
\hline & Model & PP amp (cm) & $M_{L}$ \\
\hline \multicolumn{4}{|l|}{ FTS-AVR } \\
\hline & Const. L & 63.2 & 7.5 \\
\hline & Const. D $(\tau=3 \mathrm{sec})$ & 17.8 & 7.1 \\
\hline & $\mathrm{R}(2,3.0)$ & 33.4 & 7.0 \\
\hline & $\mathbf{R}(2,2.0)$ & 39.9 & 7.1 \\
\hline & $R(4,3.0)$ & 31.2 & 7.2 \\
\hline & $\mathrm{R}(2,5.0)$ & 28.4 & 7.1 \\
\hline & $\mathbf{R}(2,1.0)$ & 49.9 & 7.2 \\
\hline & $\mathrm{R}(2,4.0)$ & 32.9 & 7.2 \\
\hline & $\mathrm{R}(4,2.0)$ & 34.8 & 7.1 \\
\hline & $\mathrm{R}(5,2.0)$ & 32.1 & 7.2 \\
\hline & $\mathrm{R}(6,2.0)$ & 44.1 & 7.3 \\
\hline & $\mathrm{R}(7,2.0)$ & 40.5 & 7.1 \\
\hline
\end{tabular}

FTS-ELC

\begin{tabular}{lrr} 
Const. L & 177.5 & 8.0 \\
Const. D $(\tau=3 \mathrm{sec})$ & 51.9 & 7.4 \\
$\mathrm{R}(2,3.0)$ & 81.4 & 7.5 \\
$\mathrm{R}(4,3.0)$ & 86.1 & 7.6 \\
$\mathrm{R}(2,5.0)$ & 80.8 & 7.5 \\
$\mathrm{R}(2,1.0)$ & 155.7 & 7.6 \\
$\mathrm{R}(2,2.0)$ & 113.1 & 7.5 \\
$\mathrm{R}(2,4.0)$ & 72.9 & 7.6 \\
$\mathrm{R}(5,3.0)$ & 64.3 & 7.4 \\
$\mathrm{R}(6,3.0)$ & 85.9 & 7.6 \\
$\mathrm{R}(7,3.0)$ & 91.7 & 7.4 \\
$\mathrm{R}(8,3.0)$ & 89.7 & 7.6 \\
$\mathrm{R}(9,3.0)$ & 88.9 & 7.5 \\
R $(10,3.0)$ & 115.4 & 7.5 \\
\hline
\end{tabular}

In order to examine the effect of randomness on the ground motion, ground motions for the FTS-AVR model are computed for various values of $I$ and $\tau$. Figure 13 shows the results when $I$ is varied with $\tau$ fixed at $2 \mathrm{sec}$. Figure 14 shows the cases for variable $\tau$ with $I$ fixed at 2 . As shown by these figures, changes in $I$ and $\tau$ do not affect the major features of the computed ground motions. Similar comparisons are made in terms of response spectra in Figures 15 and 16. Although the details of the spectral structure change as the values of $\tau$ and $I$ change, the average level of the response does not depend on these parameters very much. Therefore, choice of these parameters is not very critical to the final result. 
TABLE 5

SUMmary OF THE RESUlts For the FTP MODEL

\begin{tabular}{llrl}
\hline FTP-AVR & \multicolumn{1}{c}{ Model } & PP amp $(\mathrm{cm})$ & $\boldsymbol{M}_{L}$ \\
& & & \\
& Const. L & 68.4 & 7.6 \\
& Const. D $(\tau=3 \mathrm{sec})$ & 16.9 & 7.2 \\
R $(2,2.0)$ & 48.2 & 7.2 \\
R $(2,3.0)$ & 49.5 & 7.3 \\
R $(4,3.0)$ & 37.4 & 7.2 \\
R $(2,5.0)$ & 57.7 & 7.3
\end{tabular}

FTP-ELC

\begin{tabular}{lrr} 
Const. L & 212.7 & 8.0 \\
Const. D. $(\tau=3 \mathrm{sec})$ & 42.8 & 7.6 \\
$\mathrm{R}(2,3.0)$ & 124.8 & 7.6 \\
$\mathrm{R}(4,3.0)$ & 110.6 & 7.6 \\
$\mathrm{R}(2,5.0)$ & 151.4 & 7.7 \\
\hline
\end{tabular}

TABLE 6

Summary of the Results for the FTG Model

\begin{tabular}{llrr}
\hline & \multicolumn{1}{c}{ Model } & PP amp (cm) & $M_{\text {L }}$ \\
\hline FTG-AVR & & & \\
& Const. L & 75.4 & 7.5 \\
& Const. D $(\tau=3 \mathrm{sec})$ & 16.8 & 7.3 \\
& R $(2,3.0)$ & 41.0 & 7.2 \\
& R $(4,3.0)$ & 27.5 & 7.2 \\
& R $(2,5.0)$ & 37.3 & 7.3 \\
& R $(2,2.0)$ & 39.2 & 7.2 \\
FTG-ELC & & & \\
& & & \\
& Const. L & 205.0 & 8.0 \\
& Const. D $(\tau=3$ sec) & 55.0 & 7.7 \\
& R (2, 3.0) & 120.0 & 7.6 \\
& R (4, 3.0) & 86.4 & 7.7 \\
& R (2, 5.0) & 108.4 & 7.7 \\
\hline
\end{tabular}

TABLE 7

Summary of the Results for the P (PALMdale EARTHQUake) MODEL

\begin{tabular}{llrr}
\hline & \multicolumn{1}{c}{ Model } & PP amp (cm) & $M_{L}$ \\
\hline P-AVR & & & \\
& Const. L & 62.2 & 7.4 \\
& Const. D $(\tau=3 \mathrm{sec})$ & 18.8 & 7.0 \\
& R $(2,3.0)$ & 45.9 & 7.1 \\
& R $(4,3.0)$ & 34.4 & 7.1 \\
& R $(2,5.0)$ & 44.4 & 7.2 \\
& R $(2,2.0)$ & 45.1 & 7.2 \\
P-ELC & & & \\
& & & \\
& Const. L & 177.3 & 7.9 \\
& Const. D $(\tau=3$ sec) & 53.9 & 7.4 \\
& R $(2,3.0)$ & 110.4 & 7.6 \\
& R (4, 3.0) & 90.3 & 7.4 \\
& R $(2,5.0)$ & 110.0 & 7.7 \\
\hline
\end{tabular}


Figure 17 compares the ground motions computed for the four Fort Tejon-type earthquakes, and the Guatemala earthquake with the design earthquake Al. In Figure 17, the $R(2,3.0)$ model is used for the AVR source function. Despite large differences between these fault models regarding the fault length and geometry, the overall amplitude of the ground motion is about the same for all the models, and is about $\frac{2}{3}$ of that of A1. It may be concluded that the ground motions shown in Figure

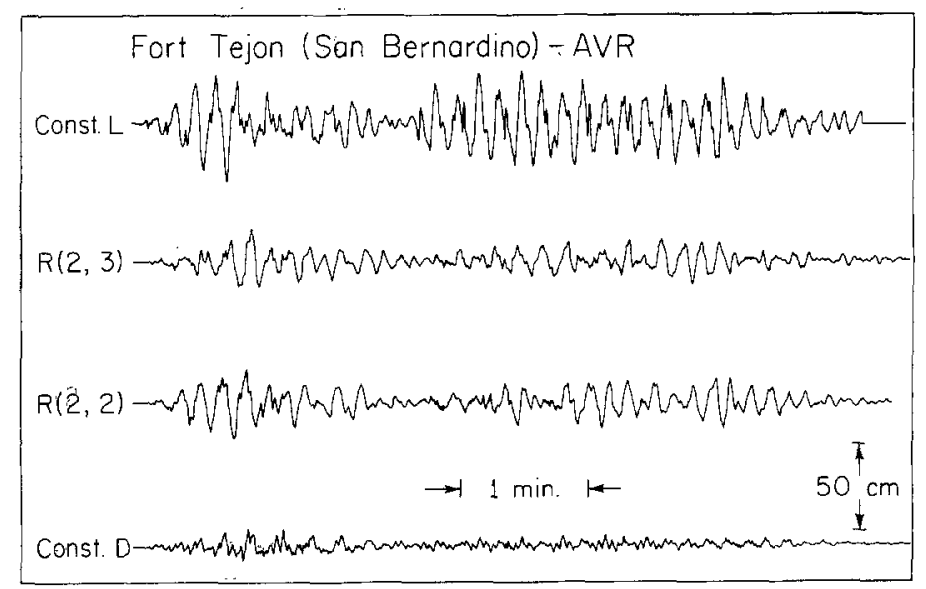

Fig. 12. Computed ground motions for the FTS model (a Fort Tejon-type earthquake which ruptured from San Bernardino). The AVR Green's function is used.

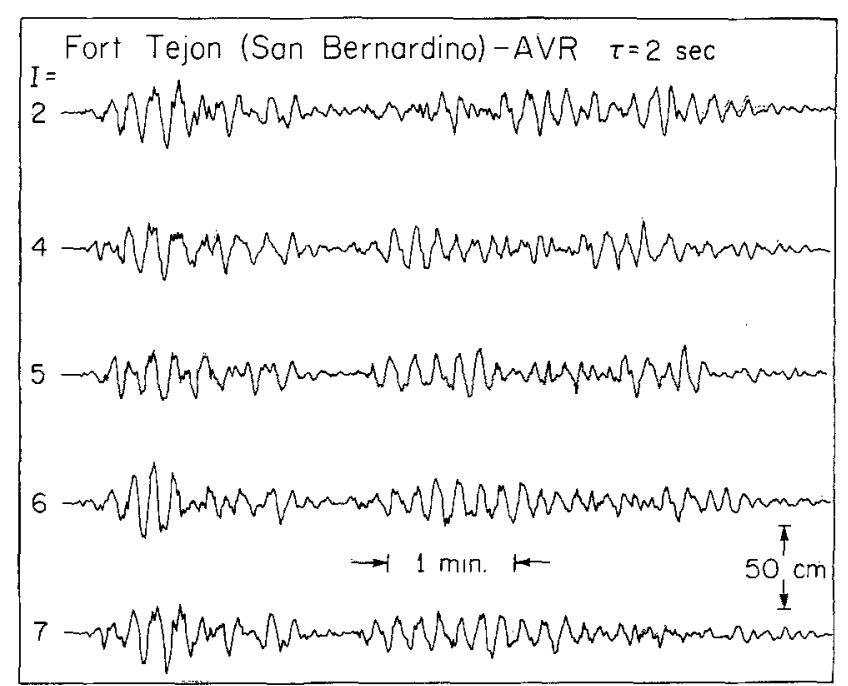

FIG. 13. The effect of index $I$ on the computed ground motions for the FTS-AVR model. $\tau$ is fixed at 2 sec.

17 represent the magnitude of long-period ground motions near a large strike slip fault of Fort Tejon type-earthquakes. We note here that two-thirds of the amplitude of the design earthquake A1 has been recommended for use in design studies of tall buildings in Los Angeles $(\Delta=60 \mathrm{~km}$ from the San Andreas Fault) (Paul Jennings, personal communication, 1979).

A similar comparison is made for the ELC source function. The result is shown in 


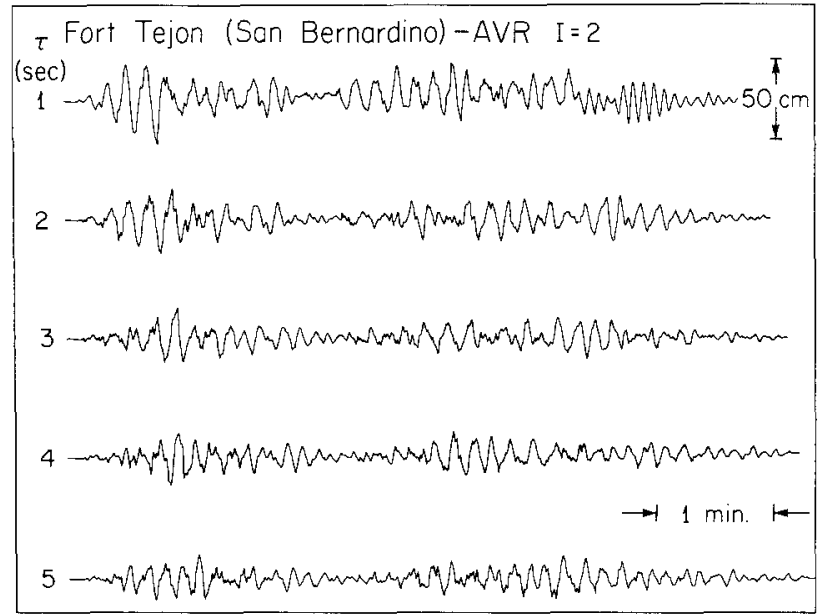

Fig. 14. The effect of $\tau$ on the computed ground motions for the FTS-AVR model. $I$ is fixed at 2.

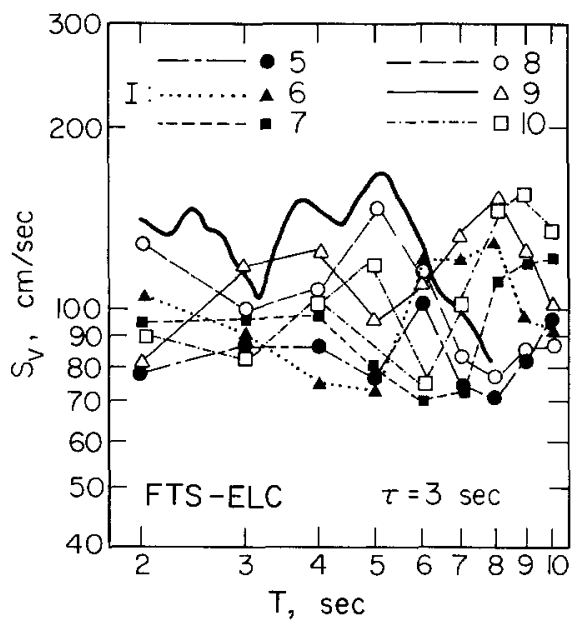

FIG. 15. The effect of index $I$ on the response spectra computed for the FTS-ELC model. $\tau$ is fixed at $3 \mathrm{sec}$.

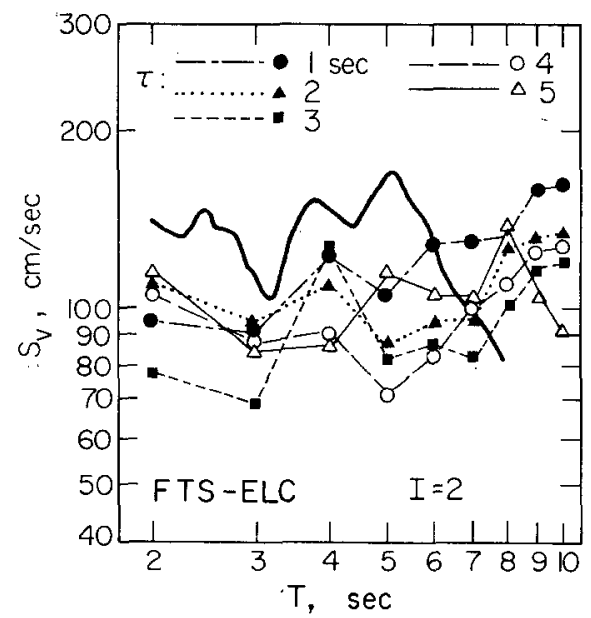

Fig. 16. The effect of $\tau$ on the response spectra computed for the FTS-ELC model. $I$ is fixed at 2 . 
Figure A4 in the Appendix. In this case the maximum amplitude of the ground motion becomes significantly larger than that for the design earthquake A1. Since the ELC record represents the very special crustal structure of the Imperial Valley, these results should not be considered representative. However, it is important to note that under certain circumstances, such as that encountered by the El Centro record, these large amplitudes can occur.

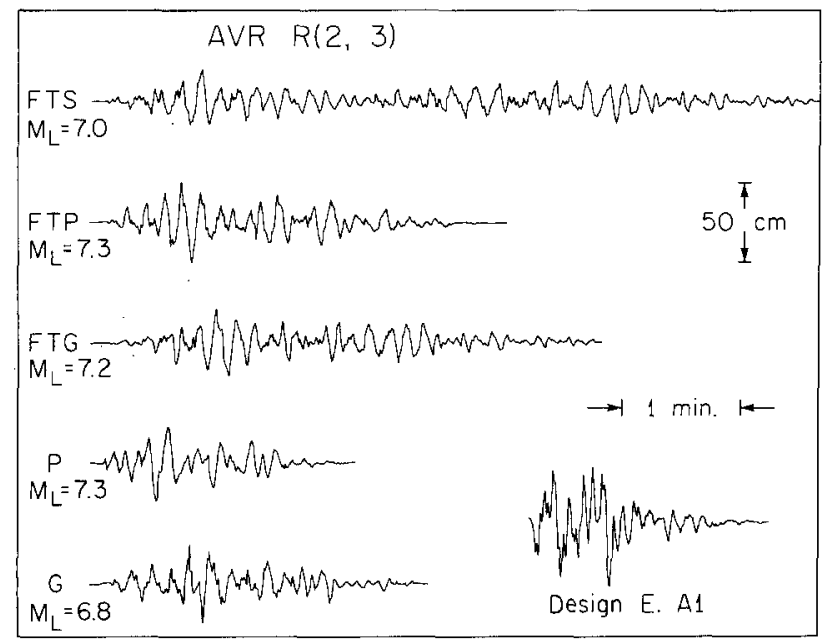

FIG. 17. Comparison of ground motions computed for the five earthquake models. Al design earthquake is shown for comparison.

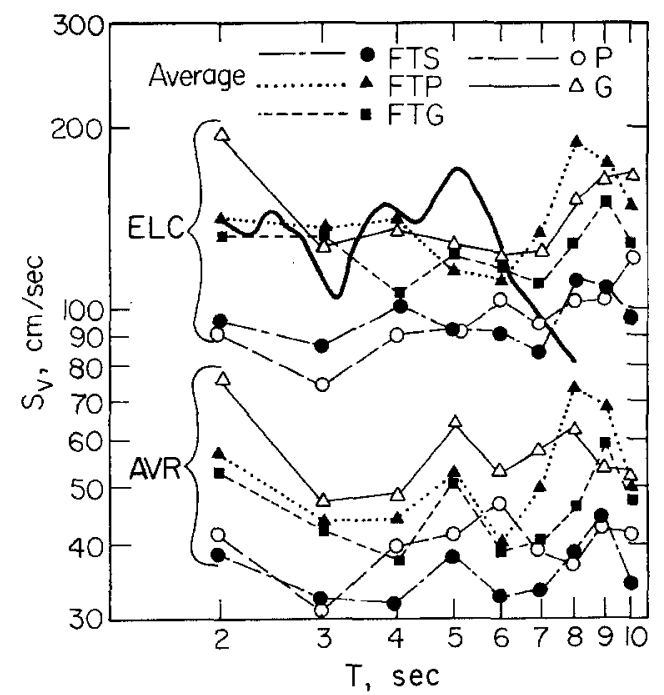

Fig. 18. Average response spectra (damping 5 per cent) for the five earthquake models. The average is taken for the three random models shown in Figures 8 and 9 . The heavy solid curve is for the Al design earthquake.

Response spectra for these ground motions are shown in Figures 8 and 9. In all of these figures, the response spectrum for the design earthquake AI is shown as reference. An important feature in these figures is that the two deterministic models, in general, bracket the random models whose response spectra are bunched together 
within a reasonably small range regardless of the difference in the parameters governing the randomness.

In order to summarize these results, the response spectra of the three random models for each model are averaged and the results are shown in Figure 18. Important features in this figure are: (1) For the AVR Green's function the average level of the spectrum for all the earthquake models is about $\frac{1}{3}$ of that of the design earthquake A1 at periods shorter than $5 \mathrm{sec}$; (2) for the ELC Green's function, the average is comparable to that of $\mathrm{A} 1$ at periods shorter than $5 \mathrm{sec}$; (3) at periods longer than $5 \mathrm{sec}$, the trend of the spectra for the computed ground motion is very different from that of A1. The former is essentially flat to at least $10 \mathrm{sec}$, while the latter rolls off very sharply at periods longer than 5 sec.

Another substantial difference between the computed ground motions and the design earthquake is in the duration of oscillations as shown by Figure 17. The

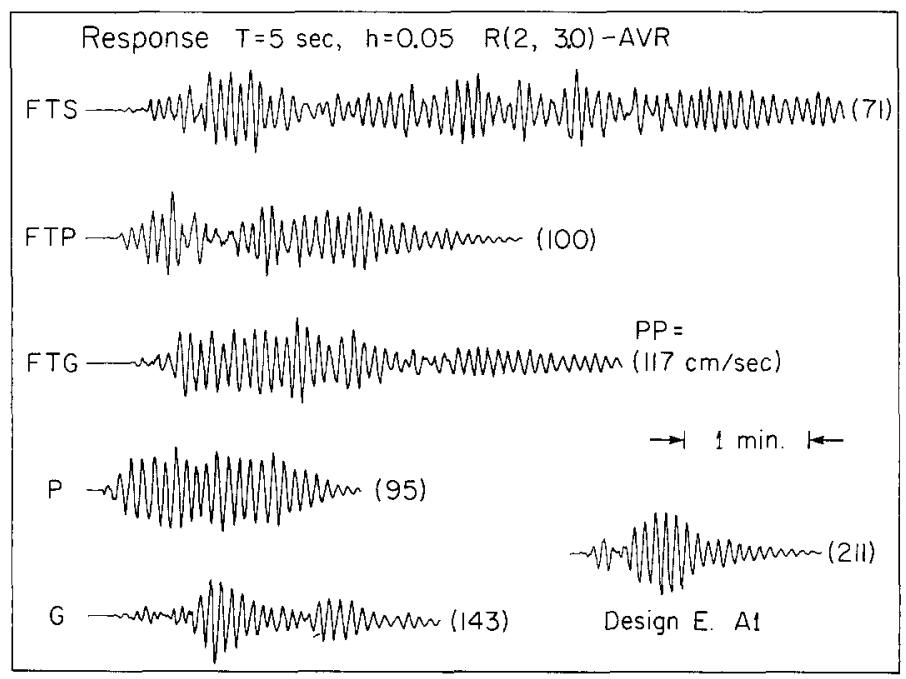

FIG. 19. The response at $5 \mathrm{sec}$ ( 5 per cent damping) computed for the five earthquake models. The random model $\mathrm{R}(2,3.0)$ is used with the AVR Green's function. The response for the Al design earthquake is shown. Note that all the traces are plotted with the same amplitude. Numbers in parentheses indicate peak-to-peak value of the velocity.

ground motion for the FTS model has the longest duration, nearly 6 min. In order to show the effect of this difference on the response, Figure 19 compares the response at $5 \mathrm{sec}$ (damping 5 per cent) for the five earthquake models and Al. In most cases, the maximum occurs in the early part of the response so that the long durations of these ground motions would not affect the response spectra. The results for the ELC Green's function are shown in Figure A5 of the Appendix.

The values of local magnitude $M_{L}$ for the models computed here are listed in Tables 4 to 7 . The average values of $M_{L}$ for random models computed with the AVR Green's function are 7.15 for the FTS model, 7.25 for the FTP model, 7.23 for the FTG model, and 7.15 for the $P$ model. These values are very reasonable in view of the result of Jennings and Kanamori (1979) who estimated that $M_{L}$ for the 1906 San Francisco earthquake is probably bounded between 6.5 and 7.25. These values are also consistent with the saturation trend of $M_{L}$ shown in Figure 2. 


\section{Discussion AND Conclusions}

Despite the recent progress in earthquake source mechanism studies, the details of the rupture propagation are still unknown. Furthermore, details of crustal structure in the epicentral area are not always known; even if they are known, complexity of the structure makes numerical computation of the propagation effect exceedingly difficult, if not impossible. In view of these uncertainties and difficulties, we chose to use a method which relies heavily on observed seismological data such as the local magnitude, $M_{L}$, the strength of multiple shocks, and observed near-field displacement records of a large earthquake. These data were used in the light of recent earthquake source models to estimate a possible range of the amplitude of strong ground motions in the epicentral areás of large strike-slip earthquakes.

In view of the complexity of the problem, we attempted to estimate the range and the average of ground motion rather than compute it deterministically. The average effect of complex rupture propagation was estimated by computing ground motions for a wide range of the random parameters which were introduced to represent the complex rupture process. The propagation path effect was averaged by taking the average of several displacement records of which the propagation path represents various geological provinces.

Although various assumptions had to be made due to the lack of our knowledge on the details of rupture propagation and the crustal structure, it is encouraging that the results are reasonable in the light of all seismological data currently available. Specifically, our results are consistent with the data at three periods of seismic spectrum: (1) At long periods, the models have the correct seismic moment of the earthquake being modeled. (2) At about $10 \mathrm{sec}$, the source is modeled by a multiple event which has complexity similar to that of very large strike-slip earthquakes. The maximum seismic moment of the individual event of the multiple shock is bound at about $5 \times 10^{26}$ dyne-cm which is the observed maximum value for large strike slip events. (3) At short periods, about $1 \mathrm{sec}$, the computed ground motions give a value 6.8 to 7.2 for $M_{L}$, which agrees with that estimated for the 1976 Guatemala earthquake and the 1906 San Francisco earthquake and is close to the observationally established upper bound of the $M_{L}$ scale.

Although the present study is concerned with ground motions from vertical strikeslip earthquakes at a period range 1 to $10 \mathrm{sec}$, the method is in principle applicable to shorter period waves and to earthquakes with a fault geometry different from strike slip. For shorter period waves, the assumptions (2) (dispersion) and (3) (attenuation), in particular (3), are no longer valid. However, if more strong-motion data become available at various distances, it would be possible to obtain empirical Green's functions at various distances. Then the assumptions (2) and (3) are no longer necessary, and essentially the same method would be applicable.

Application to other fault geometries involves further complications. First, the contribution from Rayleigh waves $(P$ and $S V)$ is no longer negligible, and the assumption (1) must be modified. Second, the simple one-dimensional rupture propagation postulated here may not be adequate for other fault geometries. In particular, the rupture propagation of large thrust earthquakes at subduction zones may be approximated more adequately by a two-dimensional propagation (e.g., Hirasawa and Stauder, 1965). In such a case, a more complex method of superposition of point sources than is used in this study would be required. Furthermore, for those thrust events, the data of $M_{L}$ and the seismic moment of the constituent event of multiple shocks are not available at present. Application of the present method 
to this type of earthquake must await accumulation of more empirical data on these events.

\section{ACKNOWLEDGMENT}

I thank Paul Jennings and Tom Heaton for discussions and information throughout this study. This research was supported by U.S. Geological Survey Contracts 14-08-0001-16776 and 14-08-0001-17631.

\section{REFERENCES}

Abe, K. (1974). Seismic displacements and ground motion near a fault: The Saitama earthquake of September 21, 1931, J. Geophys. Res. 79, 4393-4399.

Aki, K. (1968). Seismic displacements near a fault, J. Geophys. Res. 73, 5359-5376.

Brune, J. N. (1970). Tectonic stress and the spectra of seismic shear waves from earthquakes, J: Geophys. Res. 75, 4997-5009.

Burdick, L. J: and G. R. Mellman (1976). Inversion of the body waves from the Borrego Mountain earthquake to the source mechanism, Bull. Seism. Soc. Am. 66, 1485-1499.

Butler, R, and H. Kanamori (1979). Long-period ground motion from a great earthquake (submitted for publication).

California Institute of Technology (1969-1976). Strong Motion Earthquake Accelerograms, Vol. II, Part A, B, W, and Y, and Index Volume, Earthquake Eng. Res. Lab.

Hanks, T. C. (1976). Observations and estimation of long-period strong ground motion in the Los Angeles basin, Earthquake Eng. Struct. Dyn. 4, 473-488.

Hartzell, S. H. (1978). Earthquake aftershocks as Green's functions, Geophys. Res. Letters 5, 1-4.

Haskell, N. A. (1964). Total energy spectral density of elastic wave radiation from propagating faults, Bull. Seism. Soc. Am. 54, 1811-1841.

Haskell, N. (1969). Elastic displacements in the near-field of a propagating fault, Bull. Seism. Soc. Am. $59,865-908$.

Heaton, T. H. and D. V. Helmberger (1977). A study of the strong ground motion of the Borrego Mountain, California earthquake, Bull. Seism. Soc. Am. 67, 315-330.

Heaton, T. H. and D. V. Helmberger (1978). Predictability of strong ground motion in the Imperial Valley: Modeling the M4.9, November 4, 1976 Brawley earthquake, Bull Seism. Soc. Am. 68, 31-48.

Heaton, T. H. and D. V. Helmberger (1979). Generalized ray models of the San Fernando earthquake, Bull. Seism. Soc. Am. 69, 1311-1341.

Helmberger, D. V. and S. D. Malone (1975). Modeling local earthquakes as shear dislocations in a layered half space, J. Geophys. Res. 80, 4881-4888.

Herrmann, R. B. and O. W. Nuttli (1975a). Ground-motion modeling at regional distances for earthquakes in a continental interior, I. Theory and observations, Earthquake Eng. Struct. Dyn. 4, 49-58.

Herrmann, R. B. and O. W. Nuttli (1975b). Ground-motion modeling at regional distances for earthquakes in a continental interior, II. Effect of focal depth, azimuth and attenuation, Earthquake Eng. Struct. Dyn. 4, 59-72.

Hirasawa, T. and W. Stauder (1965). On the seismic body waves from a finite moving source, Bull. Seism. Soc. Am. 55, 237-262.

Jennings, P. C. and H. Kanamori (1979). Determination of local magnitude, $\boldsymbol{M}_{L}$, from seismoscope records, Bull. Seism. Soc. Am. 69, 1267-1288.

Jennings, P. C., G. W. Housner, and N. C. Tsai (1968). Simulated earthquake motions, Earthquake Eng. Res. Lab. Rep., California Institute of Technology, Pasadena.

Kanamori, H. (1972). Determination of effective tectonic stress associated with earthquake faulting, the Tottori earthquake of 1943, Phys. Earth Planet. Interiors 5, 426-434.

Kanamori, H. and D. L. Anderson (1975). Theoretical basis of some empirical relations in seismology, Bull. Seism. Soc. Am. 65, 1073-1095.

Kanamori, H. and P. C. Jennings (1978). Determination of local magnitude $M_{L}$, from strong-motion accelerograms, Bull. Seism. Soc. Am. 68, 471-485.

Kanamori, H. and G. S. Stewart (1978). Seismological aspects of the Guatemala earthquake of February 4, 1976, J. Geophys. Res. 83, 3427-3434.

Kawasaki, I., Y. Suzuki, and R. Sato (1973). Seismic waves due to a shear fault in a semi-infinite medium, 1, Point source, J. Phys. Earth 21, 251-284.

Kawasaki, I., Y. Suzuki, and R. Sato (1975). Seismic waves due to a shear fault in a semi-infinite medium, 2, Moving source, J. Phys. Earth 23, 43-61. 
Mikumo, T. (1973a). Faulting mechanism of the Gifu earthquake of September 9, 1969, and some related problems, J. Phys. Earth 21, 191-212.

Mikumo, T. (1973b). Faulting process of the San Fernando earthquake of February 9, 1971 inferred from static and dynamic near-field displacements, Bull. Seism. Soc. Am. 63, 249-269.

Prime Computer, Inc. (1977). PRIME, PDR 3057 Fortran Programmer's Guide, pp. 20-27.

Rial, J. A. (1978). The Caracas, Venezuela earthquake of July 1962: A multiple source event, J. Geophys. Res. 83, 5405-5414.

Sieh, K. E. (1978). Slip along the San Andreas fault associated with the great 1857 earthquake, Bull. Seism. Soc. Am. 68, 1421-1448.

Stewart, G. S. and H. Kanamori (1978). Complexity of rupture propagation in large earthquakes (abstract), EOS Trans. Am. Geophys. Union 59, 1127.

Swanger, H. J. and D. M. Boore (1978). Simulation of strong-motion displacements using surface-wave modal superposition, Bull. Seism. Soc. Am. 68, 907-922.

Trifunac, M. D. (1974). A three-dimensional dislocation model for the San Fernando, California earthquake of February 9, 1971, Bull. Seism. Soc. Am. 64, 149-172.

SEISMOLOGICAL LABORATORY

Division of Geological and Plianetary Sciences

California Institute of Technology

Pasadena, California 91125

Contribution No. 3250

Manuscript received May 24, 1979

\section{APPENDIX}

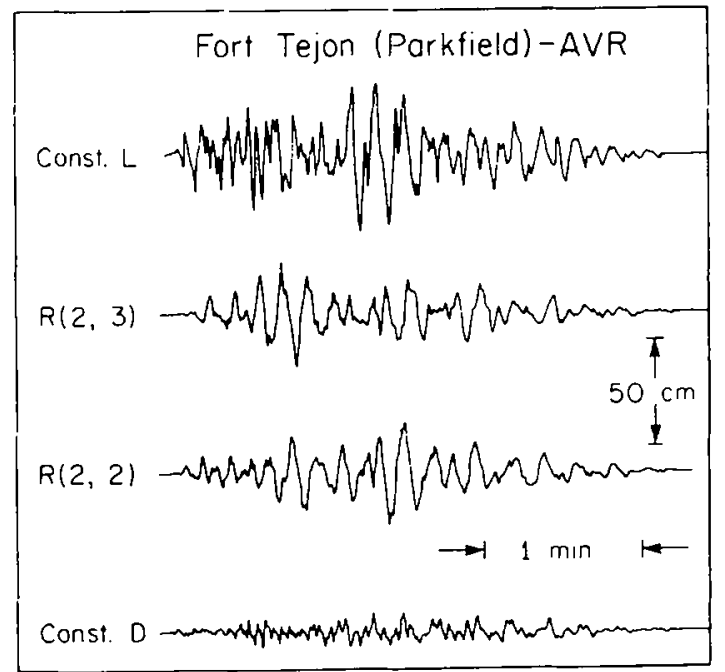

FIG. A1, Computed ground motions for the FTP-AVR model. 


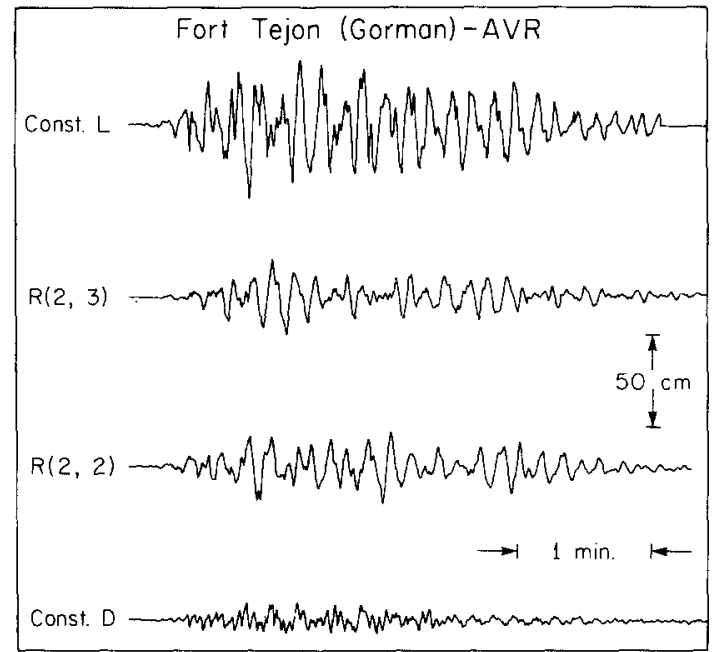

FIG. A2. Computed ground motions for the FTG-AVR model.

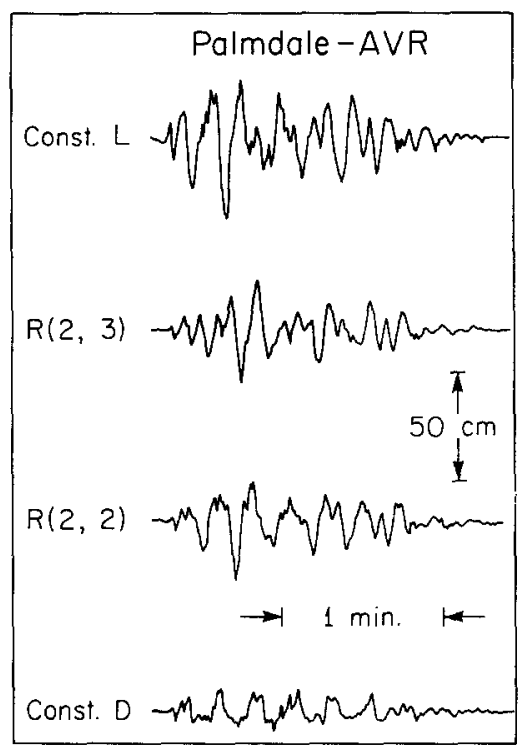

FIG. A3. Computed ground motions for the P-AVR model. 


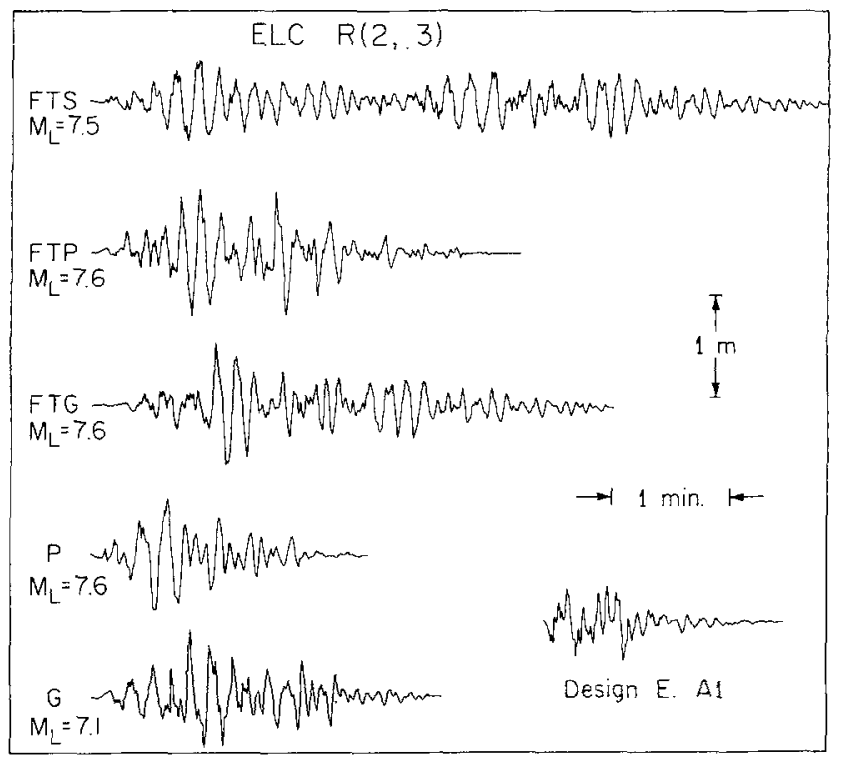

FIG. A4. Comparison of computed ground motions for the five earthquake models. The ELC Green's function is used.

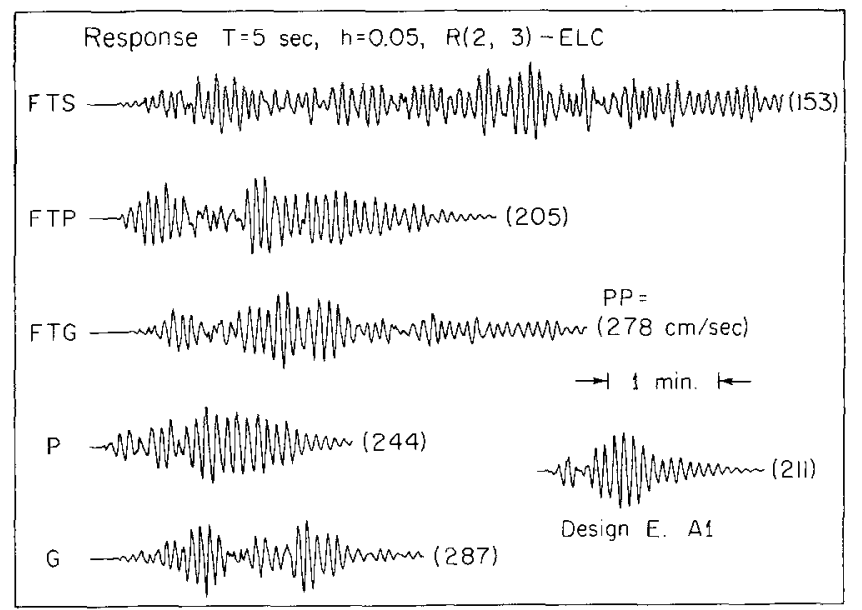

FIg. A5. The response at $5 \mathrm{sec}(5$ per cent damping) computed for the five earthquake models. The random model $R(2,3.0)$ is used with the ELC Green's function. 